"Buscar la verdad y afianzar los valores transcendentales", misión de las universidades en su artículo primero, inspirado en los principios humanísticos. Ley de Universidades 8 de septiembre de 1970.
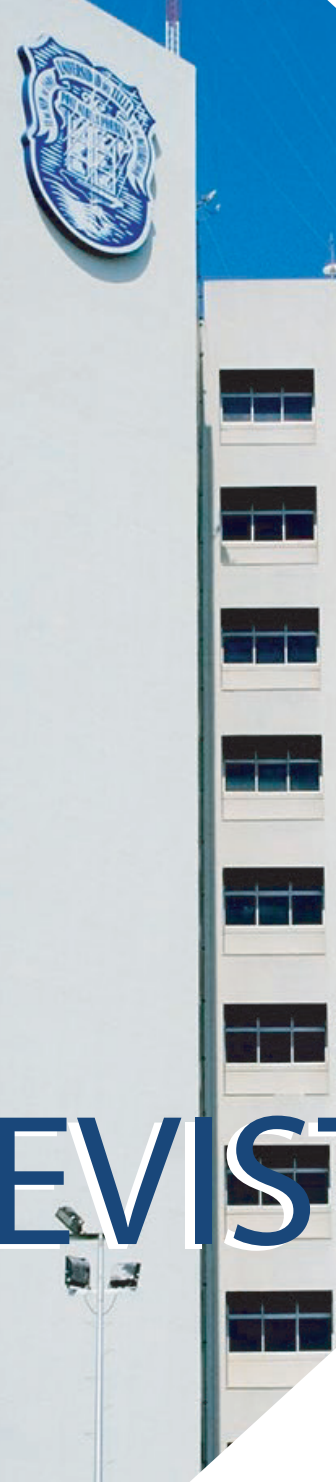
Rev. Téc. Ing. Univ. Zulia. Vol. 43, No. 2, 2020, 82-88

\title{
Study of the leaching potential in a soil and its depuration capacity: perspectives in a landfill selection
}

\author{
Jhon Fredy Narvaez ${ }^{*}$ (D), Juan José García ${ }^{1}$ D, Francisco Campillo-Machado ${ }^{1}$, Anderson
}

A. Rodríguez"; Alejandro Cardona1; Diana Patricia Urrea ${ }^{1}$

${ }^{1}$ Grupo de Investigación Ingeniar. Facultad de ciencias básicas e Ingeniería, Corporación Universitaria
Remington, Calle 51 No. 51-27, Medellín, Colombia.
*Autor de Contacto: jhon.narvaez@uniremington.edu.co
https://doi.org/10.22209/rt.v43n2a04

Recepción: 28/06/2019 | Aceptación: 17/03/2020 | Publicación: 01/05/2020

\begin{abstract}
Many differrent solid wastes are deposited in landfills which may lead to leaching processes with groundwater pollution implications. Complex fractions of organic pollutants may transfer from the soil with multiplex physicochemical interactions which reduce the final soil-borne. In this paper, we study the potential removal of a dye and the potential of water infiltration in each layer of a soil. The results show a removal $>98 \%$ in the complete profile and in the silty layer (SL) in which more infiltration was found. Therefore, organic fraction in the SL and even more interaction with the aluminum and silicates present, may reduce the dye by physicochemical interaction with $\log \mathrm{K}_{\mathrm{oc}}$ properties. Also, more infiltration in SL indicates a strong interaction between dissolve analytes and soil due to despite a large amount of water cross the silt, low infiltered levels is presented. Finally, pH slightly acid from 4.5 in the sample was increased to 6.7 which indicates basic condition for neutralization, while conductivity was reduced even to values presented in tap water due to ionic exchange capacity by the soil. A preliminary conclusion indicates that removal of the first layer in a landfill reduces the capacity of pollutants removal in soils and, therefore, low physicochemical interactions may lead to the leaching of pollutants to waterbodies. However, further experiments are needed to strengthen this study.
\end{abstract}

Keywords: soil layer; landfill; leaching processes; physicochemical interactions; water infiltration potential.

\section{Estudio del potencial de lixiviación de un suelo y su capacidad de depuración: perspectivas en la selección de un relleno sanitario}

\section{Resumen}

\begin{abstract}
Muchos residuos sólidos son depositados en rellenos sanitarios, lo que puede conducir a procesos de lixiviación con implicaciones de contaminación del agua subterránea. Las fracciones complejas de contaminantes orgánicos pueden transferirse desde el suelo con una interacción fisicoquímica que reduce su paso final al agua. En este trabajo, se evaluó la eliminación de un colorante y el potencial de la infiltración del agua en cada estrato de un suelo. Los resultados muestran una eliminación $>98 \%$ en el perfil completo del suelo y en el estrato limoso (SL) en el que se encontró más infiltración. Por lo tanto, la fracción orgánica en el SL y la interacción con el aluminio y lossilicatos presentes, pueden reducir el colorante por interacciones fisicoquímicas con propiedades de log Koc. Además, una mayor infiltración en SL indica una fuerte interacción entre el colorante y el suelo debido a que, aunque una gran cantidad de agua atraviesa los limos, se presentan bajos niveles infiltrados del colorante. Finalmente, el pH ligeramente ácido de 4,5 en la muestra se incrementó a 6,7 lo que indica una condición básica para la neutralización, mientras que la conductividad se redujo incluso a los valores presentados en el agua del grifo debido a la capacidad de intercambio iónico del suelo. Una conclusión preliminar muestra que la eliminación del primer estrato en un relleno sanitario reduce la capacidad de eliminación del suelo y, por lo tanto, pocas interacciones fisicoquímicas pueden llevar a la lixiviación de contaminantes a cuerpos de agua. Sin embargo, deben llevarse a cabo más estudios en el futuro.
\end{abstract}

Palabras clave: estrato del suelo; relleno sanitario; procesos de lixiviación; interacciones fisicoquímicas; potencial de infiltración del agua. 


\section{Introduction}

A large amount of solid waste is produced by the population growth, and thus, many cities build landfills outside, which generates multiple and complex environmental problems[1]. Therefore, the precipitation and soil properties may play an important role in pollutants final soil-borne [2]. In this aspect, the soil is a natural bio-physicochemical reactor which degrades or absorbs contaminants leaching from the solid phase and thus more polar molecules may be transported cross the soil to the groundwater due to solubility properties [3]. In contrast, non-polar pollutants may interact with organic fractions in soil by $\log k_{o c}$ properties but low interactions increase the transfer to water bodies from the soil [3]. For this reason, the total organic carbon (TOC) including humic and fulvic acids may be related to soil-pollutants interactionsas well as minerals present in the soil.

However, the pore size in soil may have an important role in absorption/ retention of a wide range of pollutants due to the molecular size and the soil granulometry may have a relationship with the potential of infiltration [4]. For instance, the clayey and even silty fraction in soils may interact by size exclusion and even by ionic interaction between organic pollutants and aluminum and silicates into the layer and therefore the removal of clay layer should not be done because absorption may decrease [5]. Therefore, incorrect landfill adequacy may lead to groundwater pollution by leaching processes. For instance, the removal of silty and clay layer reduces physicochemical interactions between molecule structures of pollutants and alumina and silicates minerals presents in those layers [6]. Although design studies about leaching treatment and infiltration are considered in landfills, no soil properties study and absorption capacity are included to reduce soil- water transport. In this paper, we focused on studying the soil properties and leaching by trace marker and leaching station to understand if a specific soil has the capacity to purify simulated wastewater and,why does this type of condition should be including in landfill selection and management to decrease ecological impact and protect water bodies influenced by leaching substances.

\section{Materials and methods}

\section{Reagents}

The dye carminic acid (Cas No. 1260-17-9) was obtained from sigmaAldrich. Miliq water was purified in a Thermo Scientific ${ }^{\circledR}$ Barnstead 50131217 GenPure $^{\mathrm{TM}}$ UV/ UF Water Purification System for Type I.

\section{Soil-layers samples}

In a polyvinyl chloride (PVC) sampler, a complete soil profile was taken from Antioquia-Colombia located at the coordinates $6^{\circ} 23^{\prime} 13.8$ “ $\mathrm{N} 75^{\circ} 35>50.8 » \mathrm{~W}$
(Latitude and Longituderespectively) and, therefore, four layers were observed with different colors and physical appearance of granulometry. Thus, the entire soil sample was separated and packed in columns (lysimeter). Figure 1 .

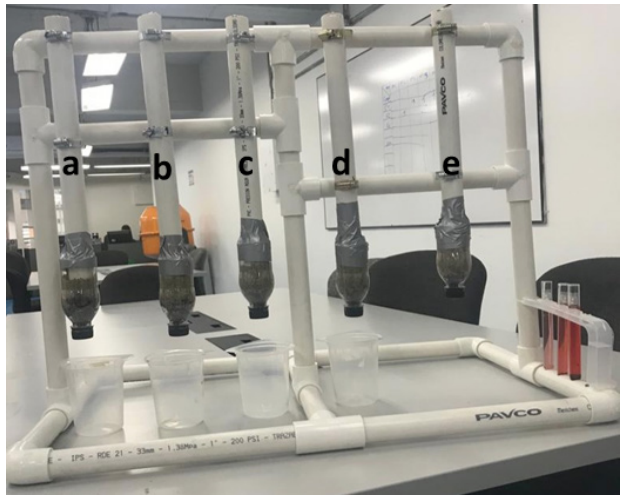

Figure 1. Lysimeter station. There are five package columns from left to right as follow: a. Complete profile (CP), b. Layer 1 (L1), c. Layer 2 (L2), d. Layer 3 (L3) and e. Layer 4 (L4)

Also, CP was built at similar percentages observed for natural profile which was sampled in a specific place according to the depthof each layer.

\section{Granulometry analysis of each layer}

All granulometry test were carry out according to the American Association of State Highway and Transportation Officials (AASHTO)methods. Thus, six sieves (TAMIZ ESTÁNDAR brand) for laboratories were used, while the Casagrande cup method (liquid limit) was performed in the Atterberg limits assay. All soil samples were weighed on digital scales and stored in tares and appropriate containers. Finally, to dry all the samples, a digital electric oven (PINZUAR brand) was used. Initially, $450 \mathrm{~g}$ of samples were dried for 24 hours in the oven. Then, the dried sample was passed through the column of six sieves and, therefore, the amount retained was weighed individually to estimate the percentage retained. Therefore, the percentage data were plotted on the granulometry curve to estimate particle size distribution. For Atterberg limits, a large number of samples were passed through sieve No. 40 to obtain $300 \mathrm{~g}$ of sample. Henceforth, 10 tares were weighed separately for the estimation of natural humidity and, subsequently, the liquid limit (LL) and the plastic limit (PL). The LL was estimated by the Casagrande cup method only to reach more than 15 strokes and less than 35 strokes, while the PL was estimated by the mold on a porous surface, such that the canes of $3 \mathrm{~mm}$ in diameter and 10 centimeters in length were obtained. 


\section{Leaching study}

For the leaching study, packed columns with the soil layer described in the previous section were used. Then, $80 \mathrm{ml}$ of simulated wastewater containing the carmine acid dye (50mg L-1, pH:4.64) were passed through the columns by the action of gravity. The volume of the solution used was calculated by means of average precipitation at the sampling site by area. Once the solution was passed, the changes between the initial condition and leaching were studied. Samples were collected in beakers for absorbance analysis by a Thermo Scientific Spectrophotometer UV-Vis Orion Aquamate 8000. Finally, the potential of water infiltration was estimated by the differences in the relationship between the initial volumetric quantity and the final volume collected in a volumetric flask.

\section{Physicochemical analysis}

The calibration curve to determine the amount of dye was used in the study of soil purification capacity. The dilutions from a concentrated solution of the carminic acid dye (50 $\mathrm{mg} \mathrm{L}^{-1}$ ) were: $1 / 5,1 / 10,1 / 20,1 / 50,1 / 100$, $1 / 200$ and $1 / 400$. Absorbance was measuredat 276 by UVVis and ther2 was estimated for linearity. For measuring dye levels in leached samples, $1 \mathrm{ml}$ was collected in a covette for UV-Vis analisys at the same lengthwave applied in calibration curve and therefore absorvances were interpolate in the linear equation. Finally, the initial and final $\mathrm{pH}$ and conductivity were measured by apH-meter/ conductivity meter instrument (Martini instrument-106).

\section{Data treatment and analysis}

All meassurements in leached samples were carry out according to standar methods (pH: ASTMD1293-14 method and electrical conductivity: ASTMD1125-18 method), and therefore, only differences between initial and final conditions were estimated by the relative standard deviation (RSD) and Nonparametric statistics were done. The analysis was plotted by GraphPad Prism 7 and by Microsoft Excel 2016. Additionally, nonparametric studies were applied for analyzing differences between treatments.

\section{Results}

\section{Granulometry study}

Less than $10 \%$ of the L2, L3 and L4 layers passed through sieve No. 200 while more than $50 \%$ managed to pass No. 40, which allowed classification in sandy, silty or clayey soils (A-2) according to the American Association of State Highway and Transportation Officials AASHTO. Next, the Atterberg limit was carried out which is presented in Figure 2.

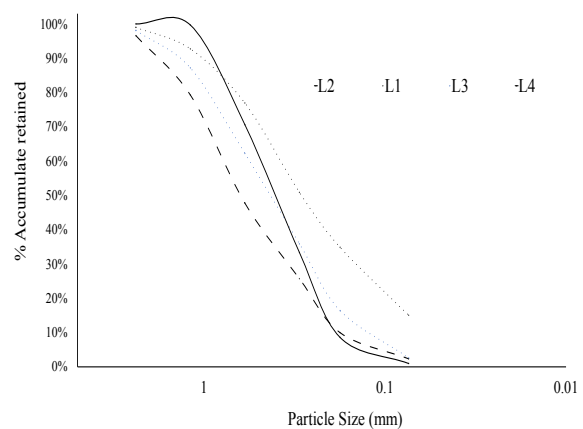

Figure 2. Granulometric distribution for all soil-layers analysis.

Due to the high percentage found through the sieve $\mathrm{N}^{\circ} 40$, the Atterberg limit for PL and LL are presented in Table 1.

Table 1. Results for Atterberg limit study in each soillayer.

\begin{tabular}{ccccc}
\hline Soil Layer & $\begin{array}{c}\text { Natural } \\
\text { humidity NH }\end{array}$ & $\begin{array}{c}\text { Liquid } \\
\text { limit LL }\end{array}$ & $\begin{array}{c}\text { Plastic } \\
\text { limit PL }\end{array}$ & $\begin{array}{c}\text { Plastic } \\
\text { index }\end{array}$ \\
\hline L2 & $29 \%$ & $55 \%$ & $45 \%$ & $10 \%$ \\
L3 & $8.9 \%$ & $66 \%$ & $57 \%$ & $9 \%$ \\
L4 & $20 \%$ & $58 \%$ & $43 \%$ & $15 \%$ \\
\hline
\end{tabular}

According to data from Table 1 and the Unified Soil Classification System (USCS) (Figure 3), L2, L3 and L4 may be classified as inorganic silty soils ( $\mathrm{MH}$ )because the LL is higher than $50 \%$ and the plasticity index is less than $20 \%$. Finally, the L1 was not studied by granulometry because their physical properties lead to classify it as an organic layer.

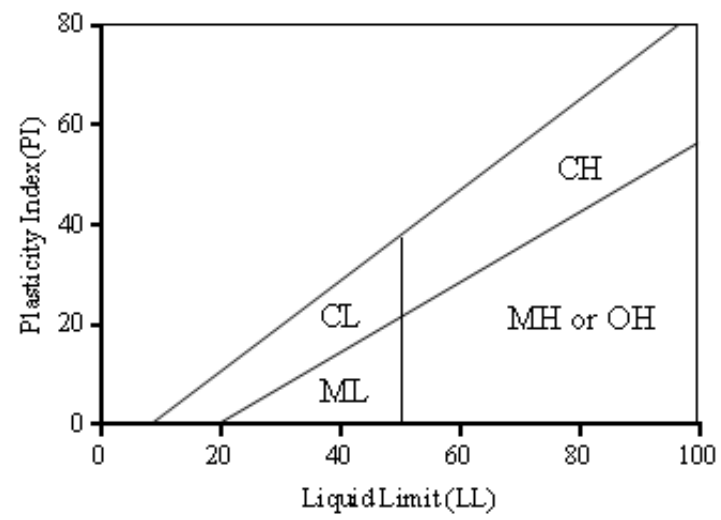

Figure 3. Plasticity index chart for Casagrande test. 


\section{Leaching study (dye removal)}

The calibration curve for quantification porposes was plotted by the relationship between the absorbance versus the dilution factor of the dye. The linear regression shown a $r^{2}$ greater than 0.98 and a nonzero slope, so the percentage of dye removal was found using the corresponding equation. For more details, see the Figure 4.

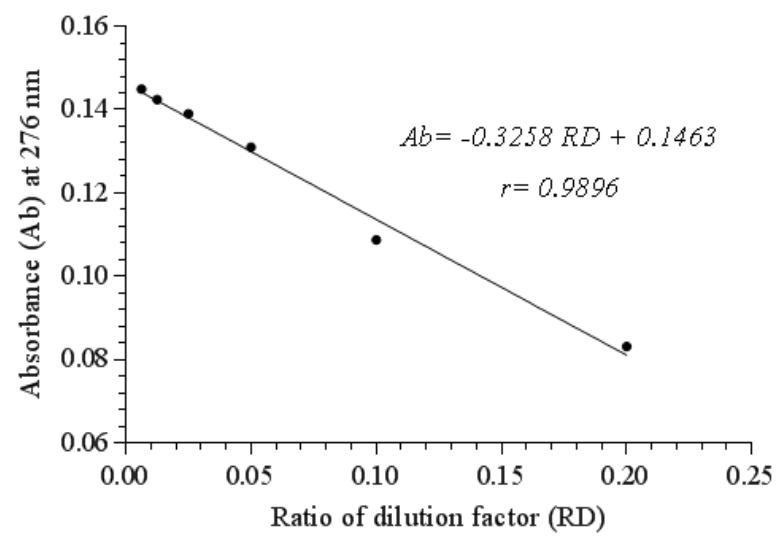

Figure 4.Calibration curve for dye removal and quantity purpose.

The absorbances measured for leached samples were analyzed by interpolation in linear equation, and, there foreitthe removal percentages found were in the range between $97.0 \%$ and $99.8 \%$, see Figure 5 for more details.

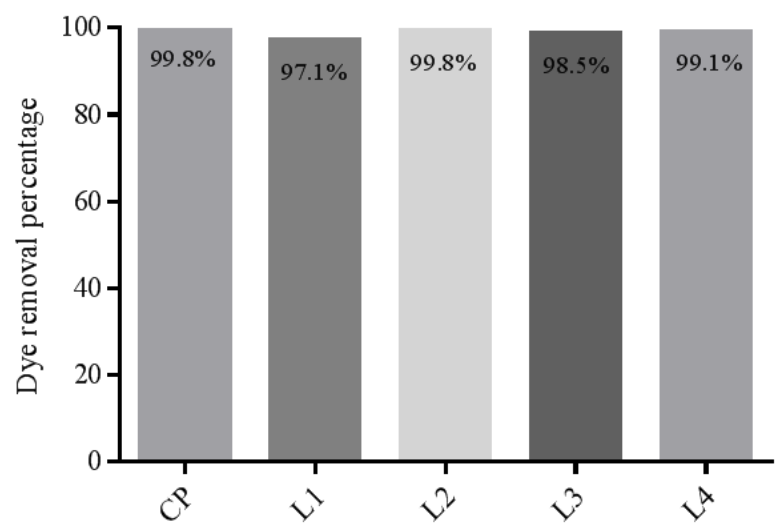

Figure 5. Dye removal percentages in the different soillayers.

The graph shows that there are no significant differences in dye removal in the soil-layers ( $p$ value $>$ $0.05)$. Therefore, in all soil layers, dye removal is carried out efficiently (values $>97.1 \%$ ). However, the removal was slightly higher in CP and L2 (silty soil layer) as can be seen in Figure 5.

\section{Physicochemical analysis in leaching water}

\section{Variability of $\mathrm{pH}$ in leaching fractions}

Figure 6 shows the $\mathrm{pH}$ variability in the leaching fractions of each soil layers, including the complete soil sample, the original dye solution and a deionized water sample as a reference. As can be seen in Figure 6, the $\mathrm{pH}$ values of every soil layers are very similar to each other, with no significant differences ( $\mathrm{p}$ value $>0.05$ ) among the values found; the average $\mathrm{pH}$ value was 6.7 , very close to neutrality, which indicates an improvement of this parameter up to 2 units.

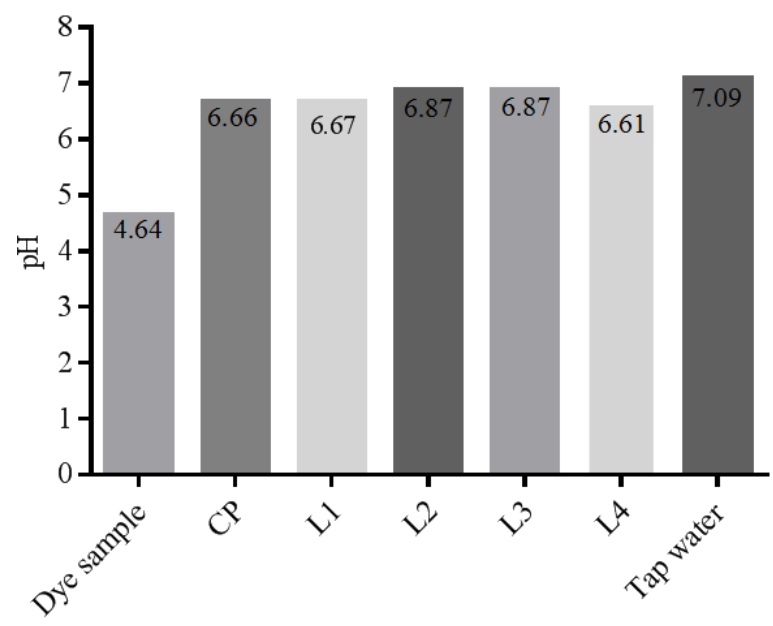

Figure 6. pH measured in leaching fractions from the different soil-layers.

On the other hand, the $\mathrm{pH}$ value of the original dye solution was 4.64 while the $\mathrm{pH}$ value of the deionized water was 7.0 used as a blank.

\section{Conductivity analysis and potential of water infiltration}

Figure 7 shows the variability in the conductivity in the leaching fractions of each of the soil layers, including the complete soil sample, the original dye solution and a tap water sample as a reference. The conductivity value of the original dye solution was reduced to values that range around $60 \mathrm{mV}$, in all cases. The conductivity values found in the leaching fractions were even lower than those found in tap water. Therefore, it can be inferred that the physicochemical interactions between the original dye solution and the soil layers could reduce the electrolytes present in the initial samples. 


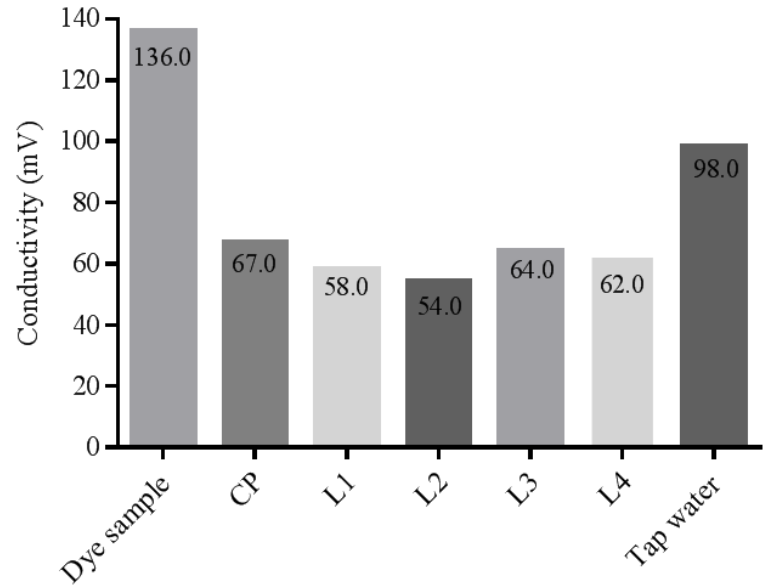

Figure 7. Conductivity in leaching fractions from the different soil-layers.

Although, a reduction in conductivity was observed in all fractions, the lowest value was found in L2 $(54 \mathrm{mV})$, showing in parallel a slightly greater dye removal compared to the rest of the soil layers.

The percentage of water infiltrated was estimated by the ratio between the volume of water infiltrated in each of the soil layers and the initial water volume, the results are shown in Table 2.

Table 2. Potential of water infiltration in the CP and soillayer.

\begin{tabular}{cccccc}
\hline \multirow{2}{*}{ Type of Volume } & \multicolumn{5}{c}{ Soil sample or soil layer } \\
\cline { 2 - 6 } & CP & L1 & L2 & L3 & L4 \\
\hline $\begin{array}{c}\text { Volume of water infiltrated } \\
(\mathrm{mL})\end{array}$ & 20.0 & 30.5 & 48.5 & 19.0 & 12.0 \\
$\begin{array}{c}\text { Percentage of water } \\
\text { infiltrated (\%) }\end{array}$ & $\mathbf{2 5 . 0}$ & $\mathbf{3 8 , 1}$ & $\mathbf{6 0 . 6}$ & $\mathbf{2 3 . 8}$ & $\mathbf{1 5 . 0}$ \\
\hline
\end{tabular}

Initial volume of water - $80 \mathrm{~mL}$

The values of the percentage of water infiltration were very different among all soil samples ( $\mathrm{CP}$ and soil layer). In the case of layer L2 (silty layer), quite higth percentage of infiltrated water was obtained (60.6\%) compared to the rest of the samples with values lower than $38.1 \%$.

\section{Results and discussion}

Although recycling and organic production are applied throughout the world, landfills continue to be a form of final disposal of large amounts of solid waste. However, precipitation over the landfill, leaching of many complex pollutantsas well as thesoil properties are not fully considered in the conventional design. Although there are forms of leachate treatment in the landfill, groundwater can be the destination of many substances causing pollution[7]. In this article, the leaching potential of a soil was analyzed as well as its purification capacity using the carminic acid dye as a trace marked in order to establish some soil properties which should be considered as an important aspect in the selection of a landfill site, in order to reduce negative effects on environment. Some works have been carried out with a similar orientation to the present study [8-9], however, the soil-layer purification capacity, as well as its effects on leachate, are not fully understood and, thus, more research and knowledge must be obtained in order to improve the site selection process in which the landfill will be established.

The granulometry study including Atterberg limit showed that layers L2, L3 and L4 are close to similar in silty properties, while L1 showed organic properties due to the origin of the soils, which is related to volcanic ash. Likewise, according to national cartography the soil in this study area is classified as a modal profile A330 with organic properties between 18 to $25 \mathrm{~cm}$ deep. The SL found in some layers includes the presence of silicates, aluminum and low amounts of iron which may take part in physicochemical reactions for degradation of the dye and alsothe pore size in the different SL may catch some substances due to their particles are lower than $4.5 \mu \mathrm{m}$ in a distribution higther than $60 \%$ [10]. For instance, the silica gel which is applied for chromatography separation includes particle size between 38 to $63 \mu \mathrm{m}$ and thus the retention by physical interaction is done [11-12]. Similarly, this interaction may be found in silty fractions which containsa particle sizes distribution smaller than silica gel used in chromatography and, therefore, the adsorption capacity may be higher in those layers. In a research study, it was found that silty loam layer does not lead to the volatilization of kerosene, because the hydrocarbons are caught by the smaller pore sizes[10]. According the present study, the carminic acid is removed in all soil-layers. However,a slightly more reduction of dye is found in CP. Additionally, the conductivity is reduced by more than $50 \%$ and, the initial $\mathrm{pH}$ in the dye sample is neutralized in this prepared column. Evidently, the CP contain all the individual properties presented in layers analyzed by separate and, thus the granulometry, silt, plasticity and organic matter contained in each layer may affect together the transport of the carminic acid. For instance, the first organic layer (presented as L1) in $\mathrm{CP}$, can retain the dye by organic interactions including those indicated by the organic carbon partition coefficient $(\log K o c)$. Loffredo and N. Senesi have shown that humic acids (HA) which are the most abundant fraction in soil organic mattermay affect the adsorption/desorption of pharmaceutical compounds because the HA are rich in hydrophilic and hydrophobic sites which increase the interactions between this fraction and the organic pollutants[13]. Therefore, the analysis of total organic carbon (TOC) may be an important issue in the soil selected as a landfill because this is an important value for $\log K_{o c}$ interaction between xenobiotic substances and 
soil [14-15]. Additionally, the organic pollutants may be caught and degraded by microbiota and physicochemical factors such as sunlight, $\mathrm{pH}$ and temperature in organic phases in L1 [16-17].

The silty properties found in CP are related to ratios of L2, L3 and L4 in the simulated soil and therefore, the adsorption is improved slightly due to particle size or silica-aluminium interaction with carminic acid as was presented before. In individual layers no differences were found in dye removal (Figure 5) and thus the carminic acid adsorption may be related to complex interactions such as polyelectrolytic character, surface area (interaction with particle size in soil) and hydrophobic interactions [13].

However, the ionic character of carminic acid may be affected by $\mathrm{pH}$ and thus this parameter was tested. The pKa1 for carminic acid (2.81) showed that $\mathrm{pH}$ in the medium may change the chemical dissociation and therefore, their solubility and infiltration. For instance, the $\mathrm{pH}$ in initial samples was close to 4.67 which is a value for a non-ionized form of carminic acid and thus the maximum adsorption may occur in soil. In Figure 8,an ionic grup in the molecular structure of carminic acid is presented, which may affect the chemical ionization by $\mathrm{pH}$ variability in medium.<smiles>Cc1c(C(=O)O)c(O)cc2c1C(=O)c1c(O)c([C@H]3O[C@H](CO)[C@@H](O)[C@H](O)[C@H]3O)c(O)c(O)c1C2=O</smiles>

Figure 8. Molecular structure of carminic acid.

According to Figure 8, the carboxylic and even the hydroxyl group affect the ionic form in carminic acid. Additionally, the surface area and the high molecular weight may be related to adsorption due to the thin pore size in soil. Likewise, the molecular structure shows a bi-dentate ligand (carboxyl and the orthohydroxy groups) which may ligand and coordinate metal ions[18]. This may be the explanation why the conductivity was reduced, because hypothetically the absorbed carminic acid may interact with ions which pass through the soil column [18]. Even more, in pH experiment (see Figure 6), this parameter was the most relevant condition for transport of pollutants, which is the reason why although, the percentage of water infiltrated (PWI) was higher than $15 \%$ in all layers the carminic acid was not detected in leaching water even in L2 which presented the highest
PWI (Table 2). Since the non ionizablecarminic acid is affected by $\mathrm{pH}$, its water solubility is decreased and only the water may cross layers. Similar effects are found for ionizablepollutants. Major pharmaceutical products are weak acids and bases and thus, those products may be soil-borne to water in landfills due to $\mathrm{pH}$ conditions. For instance, according to Hao Chen, the ciprofloxacin may show higher mobility at pH 5.6 [19].

Finally, the carminic acid is a degradable substance by biological and physical processes and their stability was not considered in this study [20]. Thus, the carminic acid adsorbed in the porous soil may be degraded by allocthonous microbiota and the delay fractions may be subsequently released. However, for persistent organic pollutants(POPs) their delay in release into the soil is unknown and, therefore, further studies should be performed. Some studies show that brominated flame retardants(BFRs) such as polybrominated diphenyl ethers (PBDEs) and tetrabromobisphenol-A may leach at levels close to $11 \mu \mathrm{g} \mathrm{L}^{-1}$ from electric waste and electronic equipments deposited in landfills which may contaminate waterbodies [21]. For this preliminary study, we may say that soil with similar properties may be prepared as a landfill but the removal of the organic layer and silty layersin soil should not be done, and likewise, the $\mathrm{pH}$ in soils and leached produced should be considered in the pollutanttransport prediction and the water pollution. Thus, landfills with POPs and complex wastes should be studied in more details. For example, electronic waste and some oils are a source of pollutants such as BFRs, polychlorinated biphenyl (PCBs) and polycyclic aromatic hydrocarbons (PAHs) with complex effects over biota after their leaching.

\section{Conclusions}

In order to select places for landfill purposes, the properties of the soil and the physicochemical interactions with the possible contaminants deposited there must be considered, so that their purification and absorption in the different layers of the soil is foreseen. The first organic layer removal from soil and low silty properties may increase the passage of pollutants through the soil to reach the groundwater. However, according to this research, deeper layers of silty soil with low water infiltration and the presence of aluminum-silicates present may take an important role because the dye was highly removed. The $\mathrm{pH}$ in the medium is a critical property of weak acid and bases soil-borne because ionic fractions can be easily transported to groundwater. The soil that was studied adsorbs weak acids and therefore, similar substances may be retained in landfills soils with comparable properties. In this research, a natural biodegradable dye was used as a trace marker, therefore, otherPOPs with different physicochemical properties should be tested and their possible impact on aquatic species due to pollutants soilborne from landfills in future studies. 


\section{Acknowledgments}

Authors thanks the project Colciencias entitled "Potencial de bioacumulación de agroquímicos y contaminantes persistentes en una cuenca del oriente antioqueño: Evaluación de un problema de salud pública" (Project code 136577757707) for fundingall experiments. Also, the authors would like to express their thanks to Margrethe Even senand Yuliet A. Jimenez (Dirección de internacionalización, lenguas y Culturas extranjeras Uniremington) for theEnglish support.

\section{References}

[1] F. Calvo, B. Moreno, M. Zamorano, and M. Szanto, "Environmental diagnosis methodology for municipal waste landfills," Waste Manag., Vol. 25, (2005) 768-779.

[2] I. Mubarak, R. Angulo-jaramillo, J. Claude, P. Ruelle, M. Khaledian, and M. Vauclin, "Spatial analysis of soil surface hydraulic properties: Is infiltration method dependent?" Agric. Water Manag., Vol. 97, $\mathrm{N}^{\circ} .10,(2010)$ 1517-1526.

[3] D. Hillel, Environmental soil physics: Fundamentals, applications, and environmental considerations. Amberst Massachusetts: Elsevier, 1998.

[4] L. Tiruta-barna, A. Imyim, and R. Barna, "Long-term prediction of the leaching behavior of pollutants from solidified wastes," Adv. Environ. Res., Vol. 8, $\mathrm{N}^{\circ}$. 03, (2004) 697-711.

[5] A. T. Yeung, "Coupled Flow Equations for Water, Electricity and Ionic Contaminants through Clayey Soils under Hydraulic, Electrical and Chemical Gradients," J. Non-Equilibrium Thermodyn., Vol. 15, $\mathrm{N}^{\circ} .3,(1990)$ 247-267.

[6] B. K. G. Theng and G. F. Walker, "Interactions of Clay Minerals with Organic Monomers," Isr. J. Chem., Vol. 8, No. 3, (1970) 417-424.

[7] Z. Han, H. Ma, G. Shi, L. He, L. Wei, and Q. Shi, "Science of the Total Environment A review of groundwater contamination near municipal solid waste landfill sites in China," no. 1, 2016.

[8] Y. Avnimelech, "Leaching of Pollutants from Sanitary Landfill Models" Journal (Water Pollution Control Federation)., Vol. 51, N. 11, (1979) 27052716.

[9] H. Yan, I. T. Cousins, C. Zhang, and Q. Zhou, "Perfluoroalkyl acids in municipal landfill leachates from China: Occurrence, fate during leachate treatment and potential impact on groundwater," Sci. Total Environ., Vol. 524-525, (2015) 23-31.

[10] E. S. P. B. V, Z. Gerstl, B. Yaron, R. Chemistry, and T. V. Centre, "Kerosene is a petroleum product characterized by low viscosity and medium volatility in comparison with heavy and residual fuels. It is used for wick-fed illumination, spark ignition engines (mainly in agriculture), and aviation gas turbines Goodger)," J. Contam. Hydrol., Vol. 5, Nº. 4, (1990) 375-385.

[11] J. Zhan et al., "A simple method for the determination of organochlorine pollutants and the enantiomers in oil seeds based on matrix solidphase dispersion A simple, rapid and effective method was developed based on matrix solidphase," FOOD Chem., Vol. 194, (2015) 319-324.

[12] R. E. Majors, "High Performance Liquid Chromatography on Small Particle Silica Gel," Anal. Chem., vol. 44, $\mathrm{N}^{\circ}$. 11, (1972) 1722-1726.

[13] E. Loffredo and N. Senesi, "Fate of anthropogenic organic pollutants in soils with emphasis on adsorption/desorption processes of endocrine disruptor compounds," Pure Appl. Chem., Vol. 78, $\mathrm{N}^{\circ} .5,(2006)$ 947-961.

[14] G. Britain, "QSAR modelling of soil sorption. Improvements and systematics of log Koc vs log Kow correlations," Chemosphere, Vol. 31, N. 95, (1995) 4489-4514.

[15] J. Kukkonen and J. Pellinen, "Binding of organic xenobiotics to dissolved organic macromolecules: comparison of analytical methods," Sci. Total Environ., Vol. 152, (1994) 19-29.

[16] J. F. Narváez, J. A. Palacio, and F. J. Molina, "Environmental persistence of pesticides and their ecotoxicity: A review of natural degradation processes," Gestion y Ambiente., Vol. 15, №. 3, (2012) 27-38.

[17] S. A. Sassman and L. S. Lee, "Sorption and degradation in soils of veterinary ionophore antibiotics: Monensin and lasalocid," Environ. Toxicol. Chem., Vol. 26, N. 8, (2007) 1614-1621.

[18] H. Atabey, H. Sari, and F. N. Al-Obaidi, "Protonation equilibria of carminic acid and stability constants of its complexes with some divalent metal ions in aqueous solution," J. Solution Chem., Vol. 41, №. 5, (2012) 793-803.

[19] H. Chen, B. Gao, H. Li, and L. Q. Ma, "Effects of $\mathrm{pH}$ and ionic strength on sulfamethoxazole and ciprofloxacin transport in saturated porous media," J. Contam. Hydrol., vol. 126, № 1-2, (2011) 29-36.

[20] D. Guillermin et al., "Dyes and Pigments New pigments based on carminic acid and smectites: A molecular investigation," Dye. Pigment., Vol. 160, (2019) 971-982.

[21] M. Osako, Y. Kim, and S. Sakai, "Leaching ofbrominated flame retardants in leachate from landfills in Japan," Chemosphere., vol. 57, (2006) 1571-1579. 


\section{REVISTA TECNICA}

DE LA FACULTAD DE INGENIERIA

UNIVERSIDAD DEL ZULIA

Vol. 43. N², Mayo-Agosto 2020, pp. 58 -110

Esta revista fue editada en formato digital y publicada en Abril de 2020, por el Fondo Editorial Serbiluz, Universidad del Zulia. Maracaibo-Venezuela

www.luz.edu.ve

www.serbi.luz.edu.ve

www.produccioncientifica.luz.edu.ve 